\title{
Prolonged use of right ventricular assist device for refractory graft failure following orthotopic heart transplantation
}

\author{
Pietro Bajona, MD,${ }^{*}$ Stefano Salizzoni, MD,${ }^{*}$ Stacey H. Brann, MD, Judy Coyne, CRNP, \\ Christian Bermudez, MD, Robert Kormos, MD, and Yoshiya Toyoda, MD, PhD, Pittsburgh, Pa
}

The use of mechanical circulatory support for posttransplant right ventricular (RV) failure is well described. ${ }^{1}$ Nakatani and colleagues ${ }^{2}$ first reported on the feasibility of the right heart assist for acute RV failure after heart transplantation. However, longest possible duration of the RV support is unknown for recovery following heart transplantation. ${ }^{3}$

We report a case of successful use of a Thoratec (Thoratec Corporation, Pleasanton, Calif) ventricular assist device (IVAD) as a bridge to recovery for prolonged RV failure following heart transplantation.

\section{CLINICAL SUMMARY}

The patient was a 55-year-old (weight, $79 \mathrm{~kg}$; height, 168 $\mathrm{cm}$ ) African-American man, diagnosed with idiopathic nonischemic dilated cardiomyopathy. During the 4 months prior to cardiac transplantation, he was repeatedly hospitalized for decompensated congestive heart failure despite optimal medical therapy. He eventually required intravenous dobutamine and intra-aortic balloon pump prior to his heart transplantation. His past medical history included hypertension, dyslipidemia, mild chronic renal insufficiency (creatinine $1.4 \mathrm{mg} / \mathrm{dL}$ ), and smoking (40 pack/y). Preoperative transthoracic echocardiography (TTE) revealed a severely dilated, diffusely hypokinetic left ventricle with severe systolic dysfunction (ejection fraction [EF] $10 \%-15 \%$ ). Cardiac catheterization on dobutamine revealed a mean right atrial pressure of $4.5 \mathrm{~mm} \mathrm{Hg}$; mean pulmonary artery pressure, $24 \mathrm{~mm} \mathrm{Hg}$; transpulmonary gradient, $12.5 \mathrm{~mm} \mathrm{Hg}$; pulmonary vascular resistance, $2.79 \mathrm{~d} \cdot \mathrm{cm}$. $\mathrm{s}^{-5}$; and cardiac index $2.4 \mathrm{~L} \cdot \mathrm{min}^{-1} \cdot \mathrm{m}^{-2}$.

He was deemed eligible for transplantation by our multidisciplinary team and subsequently underwent orthotopic cardiac transplantation. The donor was a 28 -year-old (weight, $89 \mathrm{~kg}$; height, $168 \mathrm{~cm}$ ) woman with a mild tricuspid regurgitation and moderate left ventricular hypertrophy. The

\footnotetext{
From the Division of Cardiothoracic Surgery, HLESI, University of Pittsburgh Medical Center, Pittsburgh, Pa.

Disclosures: None.

* These authors contributed equally to this work

Received for publication Aug 13, 2008; accepted for publication Oct 9, 2008; available ahead of print March 9, 2009.

Address for reprints: Yoshiya Toyoda, MD, PhD, Cardiothoracic Transplantation, The Heart, Lung, and Esophageal Surgery Institute, University of Pittsburgh Medical Center, 200 Lothrop St, C-900 PUH, Pittsburgh, PA 15213 (E-mail: toyoday@ upmc.edu).

J Thorac Cardiovasc Surg 2010;139:e53-4

$0022-5223 / \$ 36.00$

Copyright (c) 2010 by The American Association for Thoracic Surgery

doi: $10.1016 /$ j.jtcvs. 2008.10 .042
}

ischemic time was 264 minutes. Cardiopulmonary bypass was weaned with multiple inotropes, nitric oxide, and intraaortic balloon pump support due to severe RV failure. Eventually, a Bio-Medicus (Medtronic, Minneapolis, Minn) RV assist device (RVAD; right atrium to pulmonary artery) support of 4 to $5 \mathrm{~L} / \mathrm{min}$ was instituted, with immediate hemodynamic improvement, and after 72 hours RVAD was weaned successfully. However, over the ensuing 4 days, the patient's clinical condition worsened with an incipient renal failure and overlap of bradycardia. We performed an echocardiogram, which showed right ventricle failure with progressive elevation of right-sided filling pressures (central venous pressure, $35 \mathrm{~mm} \mathrm{Hg}$ ) and poor cardiac output. After the implantation of a right-sided dual-chamber pacemaker, more chronic RV support was required as a bridge to possible retransplantation, and an IVAD was inserted (Figure 1).

Over the next 53 days, there was clinical and echocardiographic evidence of progressive improvement in RV function despite severe tricuspid regurgitation. Then, RVAD explantation, combined with tricuspid valve ring annuloplasty, was successfully performed. Subsequent postoperative recovery was uneventful with good RV function, and the patient was discharged home 27 days later (Figure 2).

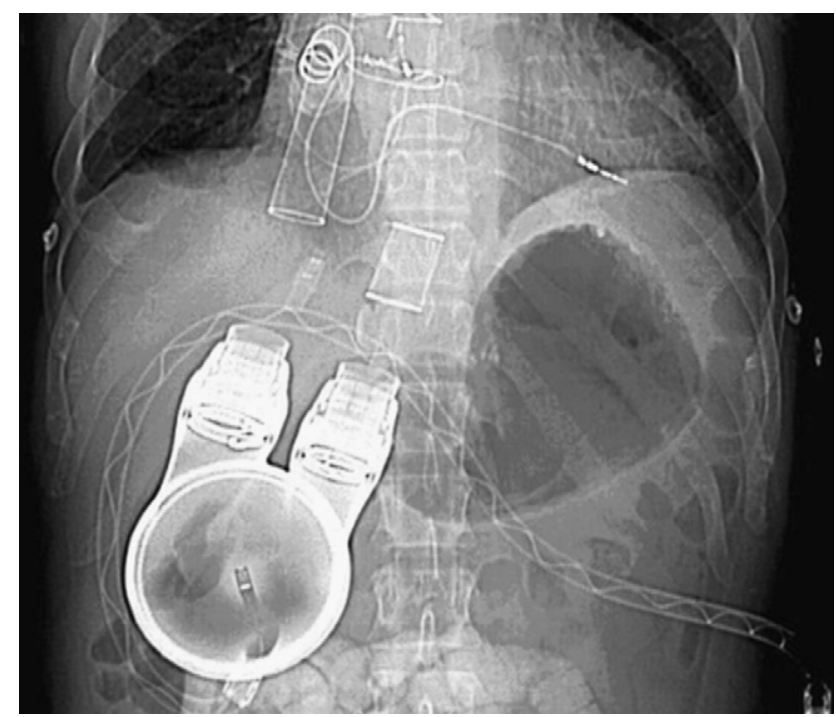

FIGURE 1. Postoperative computed tomographic scan showing Thoratec implantable right ventricular assist device in situ. 


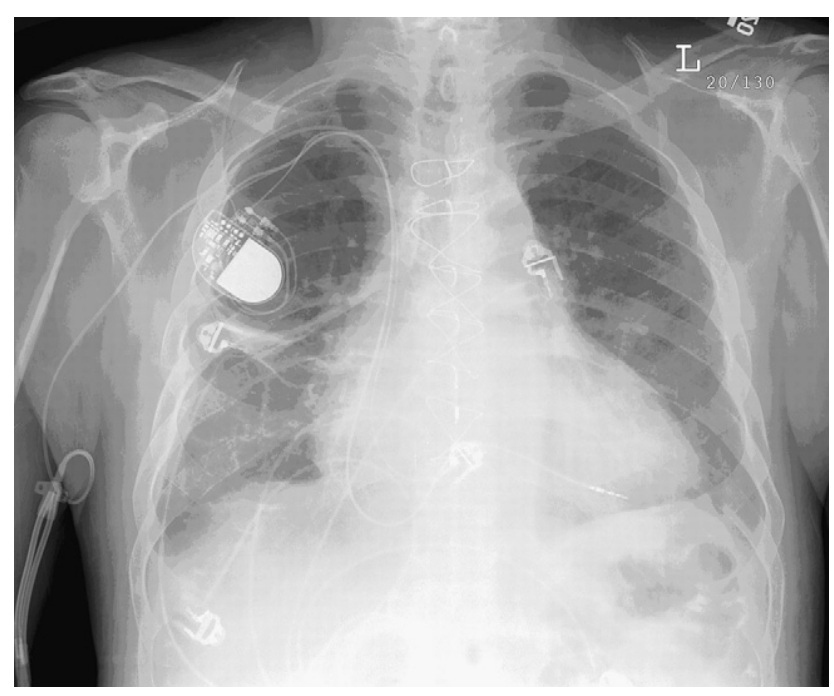

FIGURE 2. Discharge chest radiograph showing dual lead pacer in place. Pulmonary vasculature is normal. No edema, no pneumothorax. There are residual tiny pleural effusions on the right side.

At 28 months' follow-up, TTE and right heart catheterization revealed normal left ventricular size and function, EF $60 \%$; mild RV dilatation with mildly reduced RV systolic function; moderate regurgitation of the mitral and tricuspid valves, mean right atrial pressure of $4 \mathrm{~mm} \mathrm{Hg}$; and cardiac index $4.1 \mathrm{~L} \cdot \mathrm{min}^{-1} \cdot \mathrm{m}^{-2}$.

\section{DISCUSSION}

Registry data from the International Society of Heart and Lung Transplantation shows that despite advances in perioperative management, RV dysfunction is still a catastrophic event after heart transplantation. Indeed, it accounts for $50 \%$ of all cardiac complications in patients after heart transplantation and is associated with an early mortality of $19 \%{ }^{4}$

Early deaths due to RV dysfunction after cardiac transplantation are attributable to either an increase in pulmonary vascular resistance in the recipient or a loss of contractility in the donor heart. ${ }^{5}$ In this patient, it is likely that the combination of chronic pulmonary hypertension, moderate donor allograft left ventricular hypertrophy, and long cold ischemic time of the donor allograft contributed to perioperative RV dysfunction.

Chen and colleagues ${ }^{3}$ described their experience of temporary RV support, and the maximum support period time was 190 hours. The present case is unique in that the patient was successfully weaned from the RVAD after 53 days of support, and the recovered right ventricle is still functioning well more than 2 years postoperatively. To the best of our knowledge, this is the longest support to RV failure after heart transplantation. This case suggests that the RV failure following heart transplantation is reversible, and its recovery is possible beyond 50 days. We should consider the longterm use of the RVAD as an option in managing refractory primary graft failure following heart transplantation.

\section{References}

1. Stobierska-Dzierzek B, Awad H, Michler RE. The evolving management of acute right-sided heart failure in cardiac transplant recipients. J Am Coll Cardiol. 2001; 38:923-31.

2. Nakatani T, Radovancevic B, Frazier OH. Right heart assist for acute right ventricular failure after orthotopic heart transplantation. ASAIO Trans. 1987;33:695-8.

3. Chen JM, Levin HR, Rose EA, Addonizio LJ, Landry DW, Sistino JJ, et al. Experience with right ventricular assist devices for perioperative right-sided circulatory failure. Ann Thorac Surg. 1996;61:305-10.

4. Hosenpud JD, Bennett LE, Keck BM, Boucek MM, Novick RJ. The Registry of the International Society for Heart and Lung Transplantation: seventeenth official report-2000. J Heart Lung Transplant. 2000;19:909-31.

5. Kirklin JK, Naftel DC, Kirklin JW, Blackstone EH, White-Williams C, Bourge RC. Pulmonary vascular resistance and the risk of heart transplantation. J Heart Transplant. 1988;7:331-5.

\title{
Huge aneurysms of the aortic sinuses of Valsalva with leaflet perforation in an infant: A case report
}

\author{
Atsushi Kawaguchi, MD, Kenji Waki, MD, Yoshio Arakaki, MD, and Kiyoshi Baba, MD, Shizuoka, Japan
}

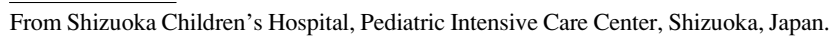
Disclosures: None.

Received for publication Dec 27, 2007; revisions received May 25, 2008; accepted for publication July 5, 2008; available ahead of print July 23, 2009.

Address for reprints: Shizuoka Children's Hospital, Pediatric Intensive Care Center, 860 Urushiyama, Aoi-ku, Szhiuoka-city, Shizuoka, 420-8660 Japan (E-mail: a-kawaguchi@sch.pref.shizuoka.jp).

J Thorac Cardiovasc Surg 2010;139:e54-6

$0022-5223 / \$ 36.00$

Copyright $\odot 2010$ by The American Association for Thoracic Surgery doi:10.1016/j.jtcvs.2008.07.068
Congenital aneurysm of the sinus of Valsalva (ASV) is a rare cardiovascular anomaly in infants. ASV usually affects only one aortic sinus and is silent until rupture occurs. Only a few cases of multiple ASV have been reported ${ }^{1-3}$ and cardiac failure resulting from aortic regurgitation in an infant with ruptured ASV is very uncommon. Here, we report the case of a 5-month-old male infant with ruptured multiple ASV and severe aortic regurgitation. 